\title{
Percutaneous Absorption Enhancers: Mechanisms and Potential
}

\author{
Letícia Norma Carpentieri-Rodrigues ${ }^{1 *}$, Juliana Modolo Zanluchi $^{2}$ and Ivanna Hinke \\ Grebogi ${ }^{1}$ \\ ${ }^{1}$ Setor de Ciências da Saúde; Faculdade de Farmácia; Universidade Federal do Paraná; Av. Prefeito Lothario \\ Meissner, 632; 80060-190; lcarpen@ufpr.br; Curitiba - PR - Brasil. ${ }^{2}$ Departamento de Ciências Farmacêuticas; \\ Faculdade de Ciências Farmacêuticas de Ribeirão Preto; FCFRP; USP; Ribeirão Preto - SP - Brasil
}

\begin{abstract}
Transdermal applications of drugs present many advantages in terms of absorption, however this is not easily obtained through the transdermal route. The principle barrier is the stratum corneum and one of the strategies that have been found to promote cutaneous drug penetration is through the use of absorption enhancers. Many substances have been identified as absorption enhancers. Although the list of substances that promote absorption is growing, in most cases, there is a direct correlation between the effects of absorption enhancers and their skin toxicity. The use of these substances depends therefore on studies which focus on local and systemic toxicity, as well as action mechanisms.
\end{abstract}

Key words: Absorption enhancers, cutaneous penetration, percutaneous absorption

\section{INTRODUCTION}

The study of the passage of drugs through the skin offers a great challenge in the fields of pharmacy and dermatology (Barr, 1962). Until the end of the last century, the skin was always referred in the scientific literature as an impermeable barrier to almost all the substances, with the possible exception of gases. However in last few years, numerous studies have shown that this was not a true statement. Studies carried out in the 50th century in reference to the penetration of water through isolated stratum corneum cleared up all former doubts, and today the skin was considered an important route for the systemic administration of drugs, and the stratum corneum was the main penetration barrier for the majority of the substances (Costa et al., 1993). Agents that are able to modify the function of this barrier are known as absorption enhancers (Finnin and Morgan, 1999).

This study presented a review of the research related to substances or physical methods that modified - temporarily and reversibly - the stratum corneum barrier, thus facilitating drug penetration.

\section{History and Prospects}

The idea of percutaneous absorption was raised in the XVI Century B.C. (Finnin and Morgan, 1999). In the period previous to 1877 , evidence suggested free skin penetration of a large number of substances, mainly gases and volatile substances. Between 1877 and 1900, Fleisher was able to prove, through experiments and critical evaluations, that the skin of humans and of some

\footnotetext{
Author for correspondence
} 
animals - those of the higher classes - was absolutely impermeable to all types of the substances. However, in 1904, Schgwenkenbecher proved that the theory of absolute impermeability was no longer valid. In 1950, Malkinson and Ferguson performed the first successful study concerning percutaneous absorption in human beings, demonstrating that the skin was permeable to topically administered drugs (Barr, 1962). Idson (1975) demonstrated that the epidermic barrier was the limiting factor for the percutaneous absorption and that once the drug passed through the stratum corneum of the epidermis, its absorption was guaranteed.

Currently, the study of percutaneous absorption has been a priority in the pharmaceutical research as it presentes an alternative route for drug administration, overcoming some of the disadvantages of oral administration, such as the hepatic first-pass effect, or other adverse effects (Cordeiro et al., 1997; Finnin and Morgan, 1999; Idson, 1975; Kitagawa et al., 1998).

\section{Cutaneous absorption}

Percutaneous absorption is the term that is most often used in reference to the passage of drugs through the skin, however many other terms may be encountered throughout literature, which include: sorption, persorption, permeation and penetration. This being the case, the use of this terminology is not restricted to a single designation (Barr, 1962).

Rothman (1954) defined percutaneous absorption as the passage of substances through the skin from one side to another, thus reaching the blood stream. According to Idson (1975), percutaneous absorption is the passage of a substance through the epidermis, dermis, blood capillaries, and/or linf channels to the blood stream. Blank (1960) stated that it wasn't necessary to have an exact definition of absorption, but that it was important to know how molecules occupied the skins surface in a determined space and time, and where they were after leaving the skins surface. According to Finnin and Morgan (1999), the advantages of obtaining cutaneous penetration consisted in the reduction in the risks of toxic effects or lack of efficacy, the ability to avoid the hepatic first-pass effect, avoid gastric irritation and chemical degradation, provide a non-invasive alternative, and also provide the convenience of a drug that could be administered to unconscious patients.
The skin has been considered a privileged site for the drug administration, as it is a crossable barrier. However, it presents a limiting factor for the penetration of some substances. Once the corneous layer has been crossed, the molecules of the drug penetrate through the live tissues of the epidermis and dermis, readily reaching the bloodstream. The corneous layer is resistant to diffusion, and does not allow substances to cross quickly, but forces them to penetrate in such a way that polar molecules pass through the water accumulated within the stratum corneum, and that apolar molecules spread out and dissolve through membrane lipids. Diffusion through the stratum corneum is a completely passive process, being that this functional barrier is the limiting factor (Lambert et al., 1989; Costa et al., 1993).

The epidermis is made up of a standard mosaic of lipids and proteins. Three routes of drug penetration through the skin are found in the literature. A transcellular route, which is responsible for drug penetration through cells of the stratum corneum; the intercellular route refers to penetration between cells and, and anexial route, which envolves the penetration of drugs through hair follicles, sweat glands, and sebaceous glands. Hair follicles and sweat glad ducts are open underneath the skin surface in the form of visible pores, and it is believed that this presents an avenue for the passage of drugs through the skin (Barr, 1962). According to Illel et al. (1991), the skin appendages have been an important pathway for absorption not only of water-soluble substances, but also, for lipid-soluble substances. Percutaneous drug absorption depends on physicochemical characteristics - which have the capacity of facilitating absorption - , as well as on the condition of the skin. Table 1 presents factors that influence percutaneous absorption.

In general, biomembranes consist of a lipophilic membrane with a hydrophilic portion. The fundamental equation which described passive drug transport through biomembranes is based on Fick's first law:

$$
J=P x C_{a q}
$$

where $\mathbf{J}$ is the flow of the drug through the membrane (mass/area/time), $\mathrm{P}$ is the permeability coefficient through the lipophilic membrane and $\mathrm{C}$ is the concentration of the drug between both 
sides of the membrane. The permeability coefficient is defined as:

$$
p=\frac{D x k}{h}
$$

where D is the drug's diffusion coefficient within the membrane, $\mathrm{K}$ is the partition coefficient of the drug from the external environment towards the membrane and $\mathrm{h}$ is the thickness of the membrane. Finally the diffusion coefficient can be estimated by Stokes-Einstein equation:

$$
D=\frac{R \times T}{6 \pi x \eta x r \times N}
$$

where $\mathrm{R}$ is the molar gas constant, $\mathrm{T}$ is the absolute temperature, $\eta$ is the viscosity of the membrane, $r$ is the radius of a spherical drug molecule permeating the membrane, and $\mathrm{N}$ is Avogadro's number.

Table 1 - Factors that influence percutaneous absorption (Finnin and Morgan, 1999).

\author{
Drug Potency (strength): The daily dose should be $\leq 20 \mathrm{mg}$ \\ Molecular size: < 500 daltons. \\ Lipophilicity: $\log \mathrm{P} \cong 1$ a 3 \\ Melting point: Should be $<200^{\circ} \mathrm{C}$ \\ Irritation: The drug should not irritate the skin \\ Imunogenicity: The drug should not stimulate imunological reactions on the skin
}

The equation demonstrates that in order for the drug to be released across the membrane, it must present some aqueous solubility, $\left(\mathrm{C}_{\mathrm{aq}}\right)$; however, at the same time, it must also possess lipophilicity and suffer partition from the external aqueous environment to the lipophylic membrane (K). By observing equation (3), it's possible to see that small molecules are able to permeate much more easily than large molecules (Loftsson, 2002).

The hydration of the skin is another factor that influences the percutaneous absorption of drugs. The greater the hydration, the higher and better the absorption of substances, in particular polar substances. Hydration is the result of the diffusion of water from adjacent layers, or of an accumulation of water - after the application of some material and/or occlusive vehicle. Other factors, such as the area and method, region, period of application, the age of the skin, and the use of vehicles which alter barrier function also influence percutaneous absorption. (Idson, 1975)

In a parallel manner, the presence of determined compounds, which act with diverse mechanisms, can provide variations in flow, due to modifications in cellular membrane structures, diffusion coefficient alterations, the partition coefficient of the stratum corneum/vehicle, influences cutaneous water content, and can also modify superficial tension. These substances are designated modifiers, accelerators, catalisors, or simply, absorption promotors. Such substances or physical methods, usually temporarily and reversibly modify the stratum corneum barrier, assisting in drug penetration. Iontoforesis, electroporation and ultrasound - physical methods -, apart from diverse chemical absorption enhancers, are used to make this route viable as a drug administration alternative.

\section{Absorption Enhancers}

The stratum corneum barrier limits drug permeation through the skin. Only some of the drug molecules which present ideal physicochemical properties are actually able to cross this barrier. The presence of certain compounds can provoke variations of flow through the skin due to modifications within cellular membrane structures, which alter the diffusion coefficient, the aqueous cutaneous content and/or lower interfase oil-water tensions. (Pershing et al., 1990; KuriharaBergstrom et al., 1990).

Studies performed on cadaver skin conclude that these substances, known as absorption enhancers are auxillary in the permeation of drugs though the skin, in this way altering the pharmacodynamic and kinetic membrane limits (Barry and Bennet, 1987). The rupture of the highly organized lipid structure of the stratum corneum, interaction with intracellular proteins, promotion of distribution of the drug within the tissue in such a way as to create a "reservatory effect", promotion of the hydration of the stratum corneum in order to form 
polar channels that facilitate the diffusion of drugs and the co-solvent action of the stratum corneum, are some of the general action mechanisms presented by absorption enhancers. Finnin and Morgan (1999) highlight some important properties for absorption enhancers; The should be harmless (inactive pharmacologically speaking); non-toxic, non-alergenic, non-irritating; present immediate effectiveness and be reversible (after removal); be physically and chemically compatable with commercially used systems smell and oilyness; and present low cost.

There are a variety of substances which have been identified as absorption enhancers, such as alcohols, azones and derivatives, non-polar compounds, ureia and cyclic derivatives, pyrrolidones and derivatives, cyclodextrins, aprotic solvents, surfactants, and even electrophoresis, electroporation and physical ultrasound. While the list of substances that can be administered by the transdermic route continues to grow, in most cases, there is a direct correlation between the promotors effect and its skin toxicity. In this way, the use of these substances depends therefore, on studies which focus on local and systemic toxicity, as well as action mechanisms (Asbill and Michiniak, 2000). According to Sasaki et al. (1988), the physical properties and percutaneous absorption behaviors of the enhancer are always important factores which promote the occurrence of side effects.

\section{Alcohols and glycols}

A variety of solvents have been identified as 'absorption enhancers'. Ethanol, diethylene glycol, propylene glycol, manitol, hexylene glycol, polyoxyethylene glycols, among others, have been shown to increase the cutaneous permeation of inumerous compounds. The extraction of lipids with the formation of "pores" within the stratum corneum, thus increasing cutaneous hydration and solubility of the solute are general action mechanisms which have been suggested to explain the enhancing action of these substances (Pershing et al, 1990; Ho et al., 1994). The transport of nonpolar materials, such as salicylic acid, may be increased through the addition of small quantities of fatty acids or alcohols within the products formulation. The addition of small quantities of alcohol produces a significant increase in the flow of salicylic acid through the skin, being that the longer the lateral carbon chain, this being up to a length of 14 carbon atoms, the greater is the enhancing effect produced. This occurs when a small transport effect is observed. Studies using differential scanning calorimetry (DSC) suggest that a liquidification of stratum corneum lipids (Cooper, 1984).

The mechanism for the promotion of cutaneous permeation by the ethanol/water system can involve contributions from conformational queratine alterations thus increasing the hydrophilic region dominion of polar headed lipid groups, or lipid extraction. The permeability coefficient of the salicylate ion through the epidermis increases with ethanol concentrations up to 0.63 and decreases as low as 1.00 (KuriharaBergstrom, 1990).

Pershing et al. (1990) studied the influence of ethanol on the absorption of $17 \beta$-estradiol on the viable human epidermis in vivo. An increase in the flow of estradiol was observed when saturated estradiol solutions were used, reflecting the solubility increase of estradiol in ethanol and, therefore, resulting in an increase in the concentration gradient across the skin. KuriharaBergstrom et al. (1990) added that the ethanolwater system could be useful in the absorption of drugs, as it was able to increase the cutaneous hydration with the understanding that either the diffusional protein volume could be increased or membrane lipids could be extracted.

Lee et al. (1997) investigates in vitro absorption of capsaicin analog (CA) through the skin of mice. Ethanol, PEG 400, propylene glycol, and 2hydroxypropyl- $\beta$-cyclodextrin were selected to increase the percutaneous solubility and absorption of capsaicin analog. The absorption of capsaicin was higher in the presence of propylene glycol and ethanol than it was with water, 2-hydroxypropyl$\beta$-cyclodextrin, or PEG 400 . The enhancing effect of these solvents was attributed to the physical modification of stratum corneum lipids, apart from conformational and structural alterations of membrane proteins. Nokhodchi et al. (2002) investigated the influence of glycyrrhizin - in different concentrations - on the percutaneous absorption of sodium diclofenac, in the form of a hydrophilic gel (carboxymethylcellulose sodium) and an oil/water emulsion through the abdominal skin of mice. The results showed that the effect of glycyrrhizin on the flow of sodium diclofenac through the skin was dose-dependent; the hydrophilic gel form provided better permeation through the skin than that of the emulsive form. 


\section{Surfactants}

The enhancer effect of surfactants on the cutaneous penetration is minimal. The capacity that these micelles have to include molecules that present low water solubility makes their solubilization possible, and in this way, facilitates the passage of substances through the membrane or intercellular spaces. The enhancer effect is only observed when the micellar structure is broken, or if some bonding process with the surfactant is interrupted. This transition depends on the concentration of the surfactant (Sarpotdar and Zatz, 1986).

The catalyzing activity of ionic surfactant depend fundamentally on the destruction of membranes of which they originate, being that they have an affinity for $\alpha$-proteins (keratine), and when they form complexes, provoke reversible desnaturation and filament distension. The expansion of the membrane causes the formation of cavities the loss of water bonding capacity, which results in the conversion of $\alpha$-keratine to $\beta$-keratine (Idson, 1975). Sorpotdar and Zatz (1986) observed the absorption of two nonionic surfactants, polysorbates 20 and 60 . An increase in the flow of lidocaine was observed for both the surfactants in the presence of propylene glycol. The enhancing effect of polysorbate varied based on the concentration of propylene glycol, thus indicating synergism between co-solvents and polysorbates.

Ogiso et al. (1989) studied the absorption of indomethacin using laurocapram A (azone) and sorbitan monooleate. Laurocapram and sorbitane monooleate affected the diffusion of transcellular water due to a modification of the layer of stratum corneum structure, thus increasing the percutaneous absorption of the drug. Nokhodchi et al. (2003) investigated the influence of surfactants - in different concentrations - on the percutaneous absorption of lorazepam through the abdominal skin of mice. Cationic surfactants presented a greater toxicity than anionic and nonionic surfactants, therefore, the enhancing effect obeyed an inverse order. Nonionic surfactants presented an insignificant enhancer effect; however, the presence of alcohols served a synergistic effect on the skin, thus making the use of these substances possible.

\section{Essencial oils, terpenes and derivatives}

The activity of three absorption enhancers - 1 menthol, oleic acid, and lauricidine was examined using diclofenac (DH) and sodium diclofenac (DNa) as hydrophobic and hydrophilic drug models, respectively, over a silicone membrane. One of the ways to enhance the transdermal permeation of drugs is through a combination of absorption enhancers with co-solvents. The synergistic effect of ethanol on the enhancing effect was evaluated. The use of ethanol at a $20 \%$ strength lowered the flow of $\mathrm{DH}$, but significantly increased the flow of $\mathrm{DNa}$ through the treated membrane when compared to the non-treated membrane, thus suggesting that the penetration of DH occurred via a lipidic route and $\mathrm{DNa}$ by membrane pores. The permeability of $\mathrm{DNa}$ decreased with the addition of oleic acid and lauricidine. The promoter effect of 1-menthol on the permeability of DH and DNa was higher on the treated skin than on that which was not treated with ethanol, suggesting that 1-menthol increased drug permeation through both, the lipid pathways and also through membrane proteins (Maitani et al., 1996).

The permeability of benzoic acid derivatives on the pig skin treated with 1 -menthol at $1 \%$ strength and ethanol at $15 \%$ strength was evaluated. The addition of an enhancer increased the flow and permeability coefficient of benzoic acid derivatives and diminished the dependence of the permeability coefficient on the partition coefficient. The enhancer effect of 1-menthol depended on the concentration of ethanol. The highly organized structure of the stratum corneum lipid bilayer was altered by the enhancer, thus, favoring the permeation of hydrophilic benzoic acid derivatives. (Kitagawa et al., 1998). Vaddi et al. (2003) studied the activity of two terpenes presenting the same functional group (limonene oxide and pinene oxide) on the cutaneous permeation of haloperidol on human skin. The synergistic effect of alcohols - ethanol and propylene glycol - on the promoting activity of terpenes was also evaluated. Limonene oxide presented higher activity than pinene oxide for both of the solvents used; however, the limonene/ethanol system was significantly more effective.

\section{Sulfoxides and analogues}

Dimethyl-sulfoxide (DMSO), dimethyl-formamide (DMF), dimethyl-acetamide (DMA) and decyl- 
methyl-sulfoxide (DCMS) were the principle substances of this group. On a structural level, a reversible configurational change was observed on the proteins with the substitution of water molecules for DMSO. The swelling phenomenon can induce the formation of channels within the matrix of the stratum corneum, which favors the passage of various compounds, or diminishes the diffusional resistance of the stratum corneum (membrane weakening). The dermal inflammation and heat produced by the interaction of the solvent and water of the stratum corneum, conducts a temperature increase and consequently the increase of stratum corneum permeability. The activity of DMSO is concentration-dependent. A positive response was observed with enhancer concentrations exceeding 60\%. Despite the excellent enhancer effect of these solvents, their use is limited due to their odor and toxicity as well as being highly irritating (Kurihara-Burgstrom et al., 1986; Idson, 1975).

DCMS, the most potent promotor among aprotic solvents, shows reversible action and is considered a good absorption enhancer for hydrophilic and ionized molecules (Santos and Bahia, 1995).

The effect of two pyrrolidones (2-pyrrolidone and $\mathrm{N}$-methyl-2-pyrrolidone), an aprotic solvent (dimethylfomamide), propylene glycol, azone and oleic acid were investigated concerning the cutaneous penetration of betamethasone 17benzoate. Dimethylsorbate, a non-promoting solvent, was used as the solvent to evaluate the choice of the co-solvent. The promotor effect of DMF was evident, however, to a lesser degree for the pyrrolidones. Azone and oleic acid were effective when associated with propylene glycol and were not when associated with DMI, thus showing the importance of the correct choice of a co-solvent (Bennet et al., 1985).

\section{Azone and derivatives}

The enhancer effect of 1- dodecylazacycloheptan2-one (azone) on various drugs through the stratum corneum has been described by many authors. In general, lipid fluidization and alteration of biomembrane protein configuration have been described as possible action mechanisms. The choice of a vehicle is one of the factors that interfere in the enhancers activity on cutaneous permeation (Okamoto et al., 1988). The ability of azone (1-dodecylazacycloheptan-2-one) to increase percutaneous liberation of metronidazole was investigated on human skin in vitro. Azone in the concentration of $1 \%$ was just as effective as 5 or $10 \%$ concentrations; the presence of propylene glycol was fundamental in order to obtain the enhancer effect. The absorption of metronidazole in the first $20 \mathrm{~h}$ was increased 25 times in the presence of $1 \%$ azone and remained effective on the skin after a few days, indicating that the enhancer effect of azone on the skin continued for many days (Wotton et al., 1985).

Okamoto et al (1988) compared the enhancer effect of nine azacycloalkanone (5-, 6- or 7member) ring derivatives with alkyl or alkenyl (terpene) groups on the lateral (side) chains with 1-dodecylazacycloheptan-2-one (azone) on the permeation of 6-mercaptopurine (6-MP) in vivo. Pretreatment of the skin with enhancers increased the permeation and accumulation of MP in the skin. The structure-activity relationships of the nine azone derivatives allowed for the conclusion that the length of the lateral (side) chain (C10C20) has an important effect on the enhancer activity, being that lateral (side) chains of the $\mathrm{C} 10$ or C15 nature seem to be favorable; lateral (side) chains with double bonds with in the trans position have little effect on the promotor activity, however these cause a less irritating effect than those with saturated chains; the ring size (C5-C7) has little influence on the activity of azones; the number of carbonyls in the ring influenced the enhancer effect, being that compounds with an azocyclopentane monocarboxilated ring are more effective than bicarboxilated rings. Pretreatment of the skin with ethanol increased the penetration of 6-MP three times, when compared to nontreated skin.

Studies using five different azone derivatives for the cutaneous permeation of Mitomycin C (MMC) showed that the size of the azacyclic right (C5-C7) had little influence on azone activity; however, the change in size of the hydrophobic lateral (side) chain resulted in a variation in the activity of these compounds. Compounds with a shorter lateral (side) chain were shown to be more effective than longer lateral (side) chains (Okamoto et al., 1987). Lambert et al. (1989) concluded that the main action mechanism of azones consists in the fluidification of the stratum corneum through the lowering of the lipid transition temperature $\left(\mathrm{T}_{\mathrm{m}}\right)$, while the queratine of the stratum corneum seemed to be altered in the presence of azones.

The effect of the vehicle on the enhancing action of azone and derivatives on percutaneous absorption of acyclovir was studied. Four solvents 
- propylene glycol (PG), ethanol (ET), isopropanol (IPA) and isopropyl myristate (IPM) were used as the vehicles. The combination of a hydrophilic vehicle with a hydrophobic promotor favored the promotor effect, with the exception of the IPM vehicle where such sinergism was not observed. This fact could be attributed to the solubility parameter of the vehicle and the enhancer, since the polarity of the IPM and of the enhancers were similar (Okamoto et al., 1990).

\section{Acids and fatty alcohols}

The fatty acids and their esters are considered authentic absorption enhancers. Ongpipattanakul et al. (1991) studied the enhancer effect of oleic acid on polar molecules and concluded that fatty acids promoted the fluidization of stratum corneum lipids by lowering the lipid transition temperature $\left(\mathrm{T}_{\mathrm{m}}\right)$. The utilization of binary mixtures of fatty acids/alcohols with propylene glycol presented an accentuated increased synergistic effect. The length and ramification, as well as the degree of saturation of lateral (side) chains of fatty alcohols/acids influences the enhancer effect of these substances. Short chains and insaturations show a greater increase in the flow of salicylic acid when compared to long and saturated chains (Cooper, 1984).

The flow of naloxone penetration on human skin was determined using various vehicles in the presence of absorption enhancers. Some of these agents have a potencial effect on the absorption of naloxone, while others have little or no effect. The maximum flow increase was observed using fatty acids or fatty alcohols/propylene glycol. For saturated fatty acids or alcohols, the best enhancer effect was obtained for compounds with 12 carbons on the lateral (side) chain; for compounds containing an 18 carbon lateral (side) chain - oleic acid and oleic alcohol - the best effect was observed for saturated chains when compared to corresponding saturated chains. Various mechanisms have been proposed: Increase in drug solubility on the skin; the action of the solvent on lipids, and even, conformational alterations or protein membrane desnaturations (Aungst et al., 1986).

The enhancer effect of caprylic acid, lauric acid, dodecanoic acid and dodecylamine on the cutaneous permeation of naloxone, testosterone, benzoic acid, indomethacin, fluorouracil and methotrexate was evaluated in vitro. Some fatty acids increased the diffusion of naloxone, testosterone, indomethacin, and fluorouracil, but this was not the case for benzoic acid and methotrexate. Dodecylamine only increased diffusion of fluorouracil. Isopropyl myristate, toluene and propylene glycol were used as adjuvant. The enhancer effect depended on the drug, the adjuvant, and the vehicle (Aungst et al., 1990). Golden et al. (1987) showed the effectiveness of fatty acids as absorption enhancers by using cis and trans isomers of octadecenoic acid. Studies utilizing infrared (IR) spectrometry and differential scanning calorimetry (DSC) showed an increase in lipid fluidification after stratum corneum treatment with monoenoic cis acids, resulting in an enhancer effect for the flow of salicylic acid.

$\mathrm{Yu}$ et al. (1988) determined the effects of vehicles on the absorption of nicardipine compounds (free base), nicardipine hydrocloride, ketorolac acid (free base) and ketorolac tromethamine. The enhancer effects of propylene glycol, trimethylene glycol, ethanol, azone, Tween 20, water, and longchain fatty acids were investigated. Trimethylene glycol and Tween 20 presented minimal effects, azone and ethanol promoted moderate absorption, while long-chain fatty acids in combination with propylene glycol were very effective in the permeation of the tested compounds. A higher flow was observed for lipophylic compounds when compared to their salts.

Elyan et al. (1996) tested the permeation of metaproterenol sulfate, a bronchodilator with low absorption via the gastrointestinal route. Systems containing capric acid, lauric acid, or myristic acid, showed different degrees of potency in the increase of cutaneous penetration. Capric acid $\left(\mathrm{C}_{10}\right)$ was less effective than lauric acid $\left(\mathrm{C}_{12}\right)$ /myristic acid $\left(\mathrm{C}_{14}\right)$ in the cutaneous permeation of metaproterenol through the skin.

Kuramoto et al. (1996) analyzed the flow of indomethacin on snake and human skin. Fatty alcohols were used as absorption enhancers. The flow of indomethacin diminished with the increase of the number of carbon atoms. The influence of six promoters (azone, DMSO, N-methyl-2pirrolidone, lecithin, laurylether polyoxyethylene and N-N-dimethyl-m-toluamide) were compared. The flow of indomethacin increased with the addition of azone, N-methyl-2-pyrrolidone and $\mathrm{N}$ $\mathrm{N}$-dimethyl-M-toluamide.

The enhancer effect of 12 fatty acid esters of medium and chains on the penetration of ketoprofen and indomethacin was studied. 
Ketoprofen had almost the same partition coefficients of indomethacin (log $\mathrm{P}$ octanol/water $\cong 3$; however, its molecular weight and melting point were lower and their/its solubility was higher. The solubility of ketoprofen was higher for the medium chain esters. A linear relation was observed between the solubility of ketoprofen and indomethacin in esters and their permeation through the skin (Fuji et al., 2000).

\section{Urea and derivatives}

Urea is one of the constituents of what is known as the Natural Moisturizing Factor. The enhancer effect of urea is attributed to an increase of cutaneus moisture (Santos and Bahia, 1995). Urea and 3 analogues - 1-dodecylurea (DDU), 1,3didodecylurea (DDDU) and 1,3-diphenylurea (DPU) -, dissolved in 3 solvents; dimethylisosorbide (DMI), light liquid paraffin, and propylene glycol (PG), were tested as absorption promoters of a model drug - 5fluorouracil (5-FU). Urea and such vehicles were not effective in the permeation of 5-FU through the human skin. DMI and liquid paraffin did not alter the enhancer activity of urea analogues. However, an elevated enhancer effect was observed for these compounds when associated with propylene glycol. The results indicated that the choice of a vehicle clearly had an impact on the enhancer effect of the evaluated substances. Various mechanisms are proposed for the enhancer effect: rupture of the organized lipid structure between corneocytes; interaction with cellular proteins, and alterations of the partition coefficient (Log P) (Williams and Barry, 1989).

Naito and Tsai (1981) studied the effect of urea on the percutaneous absorption of indomethacin. An accentuated increase in absorption was observed for $0.5 \%$ urea concentrations; however, a significant diminishing was observed when concentrations of 2.5 and $5 \%$ urea were added. Unsatured cyclic ureas were synthesized with the objective of increasing the ability of these substances as absorption enhancers. These compounds are biodegradable, being degraded by esterases (Wong et al., 1988). The enhancer effect of urea prodrugs (cyclic ureas) on the absorption of indomethacin was investigated. Azone was used as a standard promoter for comparison. Three studied compounds presented an equal or better enhancing effect as that of azone (Wong et al., 1989).
Lippold and Hackemüller (1990) studied the Natural Moisturizing Factor - sodium lactate (NaLac) sodium pyroglutaminate (Na-PCA), and urea, sorbitol, N-hydroxyethyl lactamide (OH-Lac) and propylene glycol on the percutaneous absorption of nicotinate esters. The effect was evaluated by the amount of time necessary for erythematic induction (rubor and increase of skin temperature). All of the substances were non-effective in drug permeation, with the exception of propylene glycol, thus supporting the hypothesis that these substances competed for the queratine water of the corneocytes, reducing hydrophilic and lipophylic drug penetration.

\section{Pyrrolidones}

The promoter effect of the derivative substitutes of pyrrolidone was studied - 1-metil-2-pyrrolidone (I), 1-hexyl-2-pyrrolidone (II), 1-lauryl-2pyrrolidone (III), 1-methyl-4-carboxy-2pyrrolidone (IV) e 1-hexyl-4-carboxy-2 pyrrolidone (V), 1-lauryl-4-carboxy-2-pyrrolidone (VI), 1-methyl-4-methoxycarboxy-2-pyrrolidone (VII), 1-hexyl-4-methoxycarboxy-2-pyrrolidone (VIII) e 1-lauryl-4-methoxycarboxy-2-pyrrolidone (IX) - was studied concerning the absorption of Phenol Red (Phenolsulfonphthalein) - this being a model of a non-absorbant drug. The compounds studied presented varied degrees of lipophilicity according to the nature of their functional group. The substituted derivatives 1-hexyl and 1-lauryl showed a higher enhancer effect when compared with 1-methyl substituted derivatives. On the other hand, the addition of the 4-carboxy or 4methylcarboxy group for a 1-alkyll-2-pyrrolidone diminished the promoter effect (Sasaki et al., 1988). The combination of substituted pyrrolidone derivatives - 1-methyl-2-pyrrolidone (MP) and 1lauryl-2-pirrolidone (LP) was more effective that the isolated use of these compounds. (Sasaki et al., 1990a). The enhancer effect of the pyrrolidones on phenolsulfonphtalein was dose-dependent, low concentrations of these substances promoted a longer action time (Sasaki et al, 1990b).

The effect of various concentrations of 1-methyl (I), 1-hexyl (II) and 1-lauryl-2 pyrrolidone (III) on the penetration of phenolsulfonphthalein was examined. The enhancer effect of substitutive derivatives of pyrrolidone - 1-methyl-2pyrrolidone (I), 1-hexyl-2-pyrrolidone (II), 1lauryl-2-pirrolidone (III) - was dose-dependent. The lag-time decreased with the increase in promoter concentration. The promoter effect of II 
was reversible, while a longer time was necessary in order to remove compound II from the skin (Sasaki et al, 1990a).

\section{Cyclodextrins}

These are cyclic oligosaccharides formed by at least 6 glucose units, being that the most well known are $\alpha$-cyclodextrin ( 6 units), $\beta$-cyclodextrin (7 units) and $\gamma$-cyclodextrin (8 units), which are obtained from starch by the action of the cyclodextrine-glycosil-transferase (CGTase) enzyme (Clarke et al., 1988). The cyclodextrin ring, with an elevated number of glucose molecules, becomes very flexible, and is able to accommodate molecules in its interior. These are known as inclusion complexes. There are numerous studies concerning the effects of cyclodextrins on the topical bioavailability of the drugs. The addition of cyclodextrins in transdermal products has been used to increase or decrease the absorption of many compounds within the skin; reduce or prevent irritation; reduce or eliminate odor; control the release of fragrances; stabilize emulsions and suspensions, among other applications (Loftsson, 2000; Loftsson and Masson, 2001).

Cyclodextrins are relatively large molecules which present considerable difficulty when permeating the skin. However, the enhancer effect has been observed for cyclodextrins, thus it has been suggested that the irritating effect on the skin leads to the extraction of stratum corneum lipids, thus favoring the permeation of substances (Loftsson and Masson, 2001). Iervolino et al. (2000) studied the increase in permeation of ibuprofen in a saturated solution using a silicone membrane. Hydroxypropyl methylcellulose (HPMC) and hydroxypropyl- $\beta$-cyclodextrin $(\mathrm{CD})$ were used to establish a saturated solution. Best physical stability was observed when propylene glycol was used, when the variation of the flow of ibuprofen was proportional to the concentration of the vehicle. HPMC and CD were both effective in increasing the flow of ibuprofen and acted by different mechanisms. While HPMC acted by an inhibitation of crystal grown, $\mathrm{CD}$ affected the super saturation by increasing drug solubility.

The solubilizing potential of 2-hydroxypropyl- $\beta$ cyclodextrin (HP- $\beta-C D$ ) to solubilize methylparaben and diminish the cutaneous absorption was evaluated and compared with the nonionic surfactant hydrogenated polyoxyethylene castor oil (HCO-60). The results showed that HP$\beta$-CD increased the solubility of methylparaben in water, diminished the permeability of methylparaben on the skin by $66 \%$, and promoted the conversion of methylparaben to its less toxic metabolite, p-hydroxybenzoic acid (p-HBA). The effects of HP- $\beta-C D$ were higher than those of HCO-60. In a parallel fashion, the percutaneous absorption of HP- $\beta-C D$ was extremely low (Tanaka et al., 1995).

The effect of 2- hydroxypropyl- $\beta$-cyclodextrin (HP- $\beta-C D)$ on the permeation of liarozole was evaluated and compared with 2,6-dimethyl- $\beta-C D$ (DIMEB) as well as a formulation containing $40 \%$ propylene glycol and 10\% oleic acid (PG/AO). A small enhancer effect on the percutaneous penetration of liarozole was observed for HP- $\beta$ $\mathrm{CD}$ at $20 \%$ concentration, while a decrease in permeation was observed for DIMEB in the same conditions. The PG/AO system increased the flow of liarozole in the skin 1.7 times (Vollner et al, 1993). Arima et al. (1996) studied the enhancing effects of heptakis (2,6-di-O-methyl)- $\beta$-CD (DM$\beta-\mathrm{CD})$ and 2- hydroxypropil- $\beta$-cyclodextrin (HP$\beta-C D)$ on the percutaneous absorption of 4biphenylyacetic acid (BPAA) - a nonsteroidal antiinflammatory drug -, in hydrophilic ointment and compare with enhancing effect of $\beta$-cyclodextrin $(\beta-C D)$. All $\beta$-CD's that were analyzed increased the release of BPAA. The results suggested that the $\beta$-CD promoter effect could be a result of the increase in solubility of BPAA.

\section{Iontophoresis, electroporation and ultrasound.}

Ultrasound (phonophoresis) involves the application of an ultrasound source over a surface previously treated with the drug dispersed in a topical pharmaceutical form. The ultra-sonic energy perturbs lipid packing in the intercellular spaces of the stratum corneum by way of captivation and heating effects, thus, accelerating the penetration of the drug into the tissue (Barry, 2001).

Iontophoresis is the electric delivery of the charged molecules into the tissue - it consists in the passage of a small direct current (approximately $0.5 \mathrm{~mA} / \mathrm{cm}^{2}$ ) by an electrode holding the drug in contact with the skin. A ground-electrode placed anywhere on the body completes the electric circuit. The transport of charged molecules is driven primarily by electric repulsion of the motriz electrode. Neutral polar 
molecules may also be released by a flow of connective water induced by a current (eletroosmosis). Considerable interest has been shown concerning the possibility of transdermic release of peptides and proteins, as well as many other drugs. The density of the current per unit of area, although low, penetrates the follicular pathway (low resistance route), thus able to damage the growing skin, apart from the possible irreversible modifications in the skin itself.

The transdermal iontophoretic delivery of hydrocortisone in an aqueous solution, when added to 2-hydropropyl- $\beta$-cyclodextrin (HP- $\beta$ $\mathrm{CD}$ ), was investigated and compared with the formulations containing chemical enhancer. HP$\beta-\mathrm{CD}$ at $9 \%$ concentration increased the transdermal iontophoretic release of hydrocortisone $(1 \%)$. However, low flow values were observed when insufficient quantities of HP$\beta$-CD (3\%), or excess amounts $(15 \%)$ were used. The flow values observed in the iontophoresis-HP$\beta-C D$ system were higher than those observed in the passive permeation of hydrocortisone in a nonaqueous vehicle such as propylene glycol added to oleic acid (Chang and Banga, 1998).

In the last 10 years, a physical method known as electroporation or electropermeabilization has been widely used in biotechnology for the permeation of molecules, presenting high molecular weights through biological cells (ex. plasmids). The electroporation, contrary to iontophoresis, uses the application of highvoltages pulses (Vanbever et al., 1996). Electroporation involves the creation of aqueous pores in the lipid bilayers through the application of short electric pulses (micro-to millisecond) of approximately 100 to $1000 \mathrm{~V} / \mathrm{cm}$. A flow increase of up to 10 thousand times has been obtained for the charged molecules. Electroporation can be combined with iontophoresis to improve drug permeation (Barry, 2001).

Fentanyl is a potent opioid used in analgesia and anesthesia, being available in the form of a sterile injectable IV solution. Fentanyl is a lipophylic base $\left(\mathrm{pK}_{\mathrm{a}=} 8.9 ; \log \mathrm{P}_{\text {oct/water at } \mathrm{pH} 7,4}=717\right)$ and has a molecular weight of $336 \mathrm{Da}$. Great interest has been observed in the transdermal iontophoretic transport of fentanyl. The potential of electric methods - electroporation and iontophoresis - for the transdermal release of fentanyl was compared by Vanbever et al. (1996). Iontophoresis was performed using pulses of $0.17 \mathrm{~mA} / \mathrm{cm}^{2}$ for one hour while electroporation was done through the application of $150 \mathrm{~V}-300 \mathrm{~ms}$ pulses. The efficiency of square-wave pulses (SW) and exponentially decaying pulses (ED) to promote transdermal permeation of fentanyl were compared. In vitro studies showed the same permeation profile for both of the physical methods that were used. However, preliminary in vivo studies suggested that electroporation drastically reduced the lag time necessary to produce a therapeutic effect when compared to the passive drug diffusion $\cong 14$ h) or iontophoresis. Both of the pulses - ED and SW - were efficient in the cutaneous permeation of fentanyl. However, the quantity of fentanyl transported was higher due to ED pulses than to SW pulses. The electroporation phenomenon through the skin should occur in two stages: The first stage is dependent on voltage and consists in the creation of a permeable structure. The second stage involves maintenance or expansion of this structure or expansion of the structure and/or electrophoretic movement of molecules, this being a stage which was dependent on the duration and number of pulses. ED pulses seem to be more efficient in maintaining or expanding the permeable structure and/or electrophoretic the drug movement. The results obtained showed that the transdermic release of fentanyl by electroporation could be a promising tool for obtaining a fast analgesic effect of the drug by a non-parenteral route. Electric pulses can strongly promote the transdermal release of drugs. Factors such as voltage, duration, and number of pulses influence transdermal drug permeation.

\section{CONCLUSIONS}

The transdermic route presents many advantages for the drug absorption. There are a variety of substances that have been identified as absorption enhancers, which temporarily diminish the impermeability of the skin. While the list of percutaneous absorption enhancers continues to grow, in the majority of cases, there is a correlation between the enhancer effect and skin toxicity. According to Okamoto et al. (1988) the term absorption enhancer should be reserved to substances that significantly increase drug penetration without severe damage to the skin. The use of these substances, therefore, depends on 
studies which focus on local and systemic toxicity, as well as action mechanisms.

\section{RESUMO}

A via transdérmica para a absorção de fármacos apresenta várias vantagens, porém a absorção através desta via não é fácil de ser obtida. A principal barreira encontrada é o estrato córneo e uma das estratégias encontradas para promover a permeação cutânea de fármacos é o uso de promotores de absorção. Há uma variedade de substâncias identificadas como promotores de absorção. Enquanto a lista de substâncias de promotores de absorção percutânea vem aumentando, na maioria dos casos, há uma correlação entre o efeito promotor e a toxicidade para a pele. O emprego destas substâncias depende, portanto, de estudos enfocando a toxicidade local e sistêmica, bem como o mecanismo de ação.

\section{REFERENCES}

Asbill, C.S. and Michniak, B.B.. (2000), Percutaneous penetration enhancers: local versus transdermal activity. PSTT Research Focus, 3, 1, 36-41.

Arima, H.; Miyaji, T.; Irie, T.; Hirayama, F. and Uekama, K. (1996), Possible enhancing mechanism of the cutaneous permeation of 4-biphenylylacetyc acid by $\beta$-Cyclodextrin derivatives in hydrophilic ointment. Chem. Pharm. Bull., 44, 3, 582-586.

Aungst, B.J.; Rogers, N.J. and Shefter, E. (1986), Enhancement of naloxone penetration throughout human skin in nitro using fatty acids, fatty alcohols, surfactants, sulfoxides and amides. Int. J. Pharm., 33, 225-234.

Aungst, B.J.; Bluke, J.B. and Hussain, M.A. (1990), Enhancement of naloxone penetration throughout human skin in nitro using fatty acids, fatty alcohols, surfactants, sulfoxides and amides. Pharm. Res., 7, 7, 713-718.

Barr, M. (1962), Percutaneous absorption. J. Pharm. Sci., 51, 5, 395-409.

Barry, B.W. and Bennett, S.L. (1987), Effect of penetration enhancers on the permeation of manitol, hydrocortisone and progesterone through human skin. J. Pharm. Pharmacol., 39, 535-546.

Barry, B. (2001), Liberação Tramdérmica de Fármacos. In: Aulton, M.E. Delineamento de Formas Farmacêuticas. 2.ed. São Paulo: Artemed, pp.504536.
Bennet , S.L.; Barry, B.W. and Woodford, R. (1985), Optimization of bioavailability of topical steroids: non-occluded penetration enhancers under thermodynamic control. J. Pharm. Pharmacol., 37, 298-304.

Blank, I.H. (1960), _ J. J. Soc. Cosmetic Chemists. 11, 59. apud: Barr, M. (1962), Percutaneous absorption. J. Pharm. Sci., 51, 5, 395-409.

Cappel, M.J. and Kreuter, J. (1991), Effect of nonionic surfactants on transdermal drug delivery: I. Polysorbates. Int. J. Pharm., 69, 143-153.

Chang, S. and Banga, A. (1998), Transdermal Iontofhoretic delivery of hydrocortisone from cyclodextrin solutions. J. Pharm. Pharmcol., 50, p.635-640.

Clarke, R.J.; Coates, J.H. and Lincoln, S.F. (1988), Inclusion complexes of the cyclomaltooligosaccharides (cyclodextrins). Adv. Carb. Chem. Biochem., 46; 205-249.

Cooper, E.R. ( 1984), Increased skin permeability for lipophilic molecules. J. Pharm. Sci., 73, 8, 11531156.

Cordeiro, J.A.; Alarcon, L.; Escribano, E.; Obach, R. and Domenech, J. (1997), A Comparative Study of the Transdermal penetration of a Series of Nonsteroidal Antiinflamatory Drugs. J. Pharm. Sci., 86, 4, 503-507.

Costa, P.; Ferreira, D.C. and Souza Lobo, J.M.. (1993), Sistemas de libertação transdérmica. Rev. Port. Farm., XLIII, 3, 19-26.

Elyan, B.M.; Sidhom, M.B. and Plakogiannis, F.M. (1996), Evaluation of the effect of different fatty acids on the percutaneous absorption on metaproterenol sulphate. J. Pharm. Sci.,. 85, 1, 101105.

Finnin, B.C. and Morgan, T.M.. (1999), Transdermal Penetration enhancers: Applications, Limitations, and Potential. J. Pharm. Sci., v.88, 10, 955-957.

Fujii, M.; Hori, N.; Shiozawa, K.; Wakabayashi, K.; Kawahara, E. and Matsumoto, M. (2000), Effect of fatty acid esters on permution of ketoprofen through hairless rat skin. Int. J. Pharm., 205, 117-125.

Golden, G.M.; Michie, J.E. and Potts, R.O. (1987), Role of stratum corneum lipid fluidity in transdermal drug flux. J. Pharm. Sci., 25-28.

Ho, H.; Huang, F.; Soroloski, T.D. and Sheu, M. (1994), The influence of cosolvents on the in vitro percutaneous penetration of diclofenac sodium from a gel system. J. Pharm. Pharmacol., 46, 636-642.

Idson, B.. (1975), Percutaneous Absorption. J. Pharm.Sci., 64, 6, 901-923.

Iervolino, M.; Raghavan, S.L. and Hadgraft, J. (2000), Membrane penetration enhancement of ibuprofen using supersaturation. Int. J. Pharm., 198, 229-238.

Illel, B.; Schaffer, H.; Wepierre, J. and Doucet, O. (1991), Follicles play an important role in percutaneous absorption. J. Pharm. Sci., 80, 424-427. 
Kitagawa, S.; Hosokai, A.; Kaseda, Y.; Yamamoto, N.; Kaneko, Y. and Matsuoka, E. (1998), Perrmeability of benzoic acid derivatives in excised guinea pig dorsal skin and effects of L-menthol. Int. J. Pharm, 161, 1, 115-122.

Kurihara-Bergstrom, T.; Knustson, K.; Denoble, L.J. and Goates, C. Y. (1990), Percutaneous absorption enhancement of a ionic molecule by ethanol-water systems in human skin. Pharm. Res., 7, 7, 762-766.

Kuramoto, M.; Tanaka, T.; Makita, H.; Nakamura, Y. and Yata, N. (1996), Characteristics of shed snake skin permeability to indomethacin and fatty alcohols. J. Pharm. Pharmacol., 48, 680-684.

Lambert, W.J.; Higuchi, W.I.; Knutson, K. and Krill, S.L. (1989), Dose-dependent enhancement effects of azone on skin permeability. Pharm. Res., 6, 9, 798803.

Lee, B.J.; Lee, T.S.; Sha, B.J.; Kim, S.H. and Kim, W.B. (1997), Percutaneous absorption and histopathology of a polaxamer-based formultation of capsaicin analog. Int. J. Pharm., 159, 105-114.

Lippold, B.C. and Hackemüller, D. (1990), The influence of skin moisturizers on drug penetration in vivo. Int. J. Pharm., 61, 205-211.

Loftsson, T. (2002), Cyclodextrin and the Biopharmaceutics classification system of drugs. $J$. Incl. Phen. Macr. Chem., 44, 63-67.

Loftsson, T. (2000), Cyclodextrins in skin delivery. Allured's Cosmetics and Tolletries, 115, 10, 59-66.

Loftsson, T.; Masson, M. (2001), Cyclodextrins in topical drug formulation: theory and practice. Int. $J$. Pharm., 225, 15-30.

Maitani, Y.; Shimada, K. and Nagai, T. (1996), Lmenthol, oleic acid e lauricidin in absorption enhancement of free and sodium salt of diclofenac using ethanol treated silicone membrane as model for skin. Chem. Pharm. Bull., 44, 2, 403-408.

Naito, S. and Tsai, Y. (1981), Percutaneous absorption of indomethacin from ointment bases in rabbits. Int. J. Pharm., 8, 263-276.

Nokhodchi, A.; Nazemiyeh, H.; Ghafourian, T. ; Hassan-Zadeh, D.; Valizadeh, H. and Bahary, L.A.S. (2002), The effect of glycyrrhizin on the release rate and skin penetration of diclofenac sodium from topical formulations. IL Farmaco, 57, 883-888.

Nokhodchi, A.; Shokri, J.; Dashbolaghi, A.; HassanZadeh, D.; Ghafourian, T. and Barzegar-Jalali, M. (2003), The enhancement effect of surfactants on the penetration of lorazepan through rat skin. Int. J. Pharm., 250, 359-369.

Ogiso, T.; Ito, Y.; Iwaki, M. and Atago, H. (1989), A pharmacokinetic model for the percutaneous absorption of indometacin and the prediction of drug disposition kinetics. J. Pharm. Sci., 78, 4, 319-323.
Okamoto, H.; Tsukahara, H.; Hashida, M. and Sezaki, H. (1987), Effect of 1-alkenylazacycloalkanone derivatives on penetration of mitomycin $\mathrm{C}$ through rat skin. Chem. Pharm. Bull, 35, 11, 4605-4608.

Okamoto, H.; Hashida, M. and Sezaki, H. (1988), Structure-activity relationship of 1-alkyl- or 1alkenylazacycloalkanone derivatives as percutaneous penetration enhancers. Int. J. Pharm., 77, 5, 418-423.

Okamoto, H.; Muta, K.; Hashida, M. and Sezaki, H. (1990), Percutaneous penetration of acyclovir through excised hairless mouse and rat skin: Effect of vehicle and percutaneous penetration enhancers. Pharm. Res., 7, 1, 64-68.

Ongpipattanakul, B.; Burnette, R.R.; Potts, R.O. and Francoeur, M.L. (1991), Evidence the oleic acid exists in a separate phase within estrato córneo lipids. Pharm. Res., 8, 3, 350-354.

Tanaka, M.; Iwata, Y.; Kouzuki, Y.; Taniguchi, K.; Matsuda, H.; Arima, H. and Tsuchiya, S. (1995), Effect of 2-hydroxypropyl- $\beta$-cyclodextrin on percutaneous absorption of methyl paraben. $J$. Pharm. Pahrmcol., 47, 897-900.

Rothman, S. (1954), Physiology and biochemistry of the skin. University of Chicago Press, Chicago, III, 27. apud: BARR, M. (1962), Percutaneous absorption. J. Pharm. Sci., 51, 5, 395-409.

Perhing, L.K.; Lambert L.D. and Knutson, K. Mechanism of ethanol-enhanced estradiol permeation across human skin in vivo. Pharm. Res., v.7, n.2, p.170-175, 1990.

Santos, D. and Bahia, M. F. G. (1995), Promotores de Absorção e Penetração. Cosmetics and Toiletries, 7 , 5, 42-50. (Edição em Português).

Sarpotdar, P.P. and Zatz, J.L. (1986), Evaluation of penetration enhancement of lidocaine by nonionic surfactants through hairless. J. Pharm. Sci., 75, 2, 176-181.

Sasaki, H.; Kojima, M.; Mori, Y.; Nakamura, J. and Shibasaki, J. (1988), Enhancing effect of pyrrolidone derivates on transdermal drug delivery. I. Int. J. Pharm., 44, 15-24.

Sasaki, H.; Kojima, M.; Mori, Y.; Nakamura, J. and Shibasaki, J. (1990a), Enhancing effect of pyrrolidone derivatives on transdermal drug delivery. II. Effect of application concentration and pretreatment of enhancer. Int. J. Pharm., 60, 177-183.

Sasaki, H.; Kojima, M.; Mori, Y.; Nakamura, J. and Shibasaki, J. (1990b), Enhahcing effect of combining two pyrrolidone vehicles on transdermal drug delivery. J. Pharm. Pharmacol., 42, 196-199.

Vaddi, H.K.; Ho, P.C.; Chan, Y.W. and Chan, S.Y. (2003), Oxide terpenes as human skin penetration enahcers of haloperidol from ethanol and propylene glycol and their modes of action on estrato córneo. Biol. Pharm. Bull., 26, 2, 220-228. 
Vanbever R.; Boulengè, E.L. and Prèat V. (1996), Transdermal delivery of fentanyl by electroporation. I. Influence of electrical factors. Pharm. Res., 13, 4, 559-565.

Vollmer, U.; Müller, B.W.; Mesens, J.; Wilffert, B. and Peters, T. (1993), In vivo skin pharmacokinetics of liarozole: percutaneous absorption studies with different formulations of cyclodextrin derivatives in rats. Int. J. Pharm., 99, 51-58.

Williams, A.C. and Barry, B.W. (1989), Urea analogues in propylene glycol as penetration enhancers in human skin. Int. J. Pharm., 36, 43-50.

Wong, O.; Huntington, J.; Konishi, R.; Rytting, J.H. and Higuchi, T. (1988), Unsaturated cyclic ureas as new nontoxic biodegradable transdermal penetration enhancers I: Synthesis. J. Pharm. Sci., 77, 967-971.
Wong, O.; Tsuzuki, N.; Nghiem, B.; Kuehnhoff, J. Itoh, T.; Masaki, K.; Huntington, J.; Konishi, R.; Rytting, J.H. and Higuchi, T. (1989), Unsaturated cyclic ureas as new nontoxic biodegradable transdermal penetration enhancers II: Evaluation study. Int. J. Pharm., 52, 191-202.

Wotton, P.K.; Mollgaard, B.; Hadgraft, J. and Hoelgaard, A., (1985), Vehicle effect on topical drug delivery. III. Effect of azone on the cutaneous permeation of metronidazole and propylenoglycol. Int. J. Pharm., 24, 19-26.

Yu, D.; Sanders, L.M.; Davidson Iii, G.R. ; Marvin, M.J. and Ling, T. (1988), Percutaneous absorption of nicardipine and ketorolac in rhesus monkeys. Pharm. Res., 5, 7, 457-462. 